\title{
The indelible footmarks of the World Bank in the higher education of the developing world: The case of Ethiopia
}

Woldegiyorgis, Ayenachew Aseffa

University of Tampere, Finland (ayenachew@gmail.com)

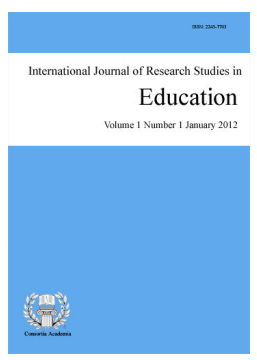

Accepted: 9 March 2014

ISSN: 2243-7703 Online ISSN: 2243-7711

OPEN ACCESS

\section{Abstract}

The World Bank, as an international policy transfer agent, has had a tremendous impact on the direction of higher education development in developing countries. It plays a significant role by mobilizing resources, generating knowledge and providing leadership. The Bank has also been a subject of serious criticisms for the approach it followed pursuing its development goals in borrowing countries. This paper explores the methods of influence used by the Bank and specifically focuses on how the World Bank has impacted the higher education system of Ethiopia. It discusses some of the criticisms against the Bank and argues that, considering the lack of institutional capacity and prevalence of corruption in Ethiopia, the Bank is, in a way, justified in its insistence on strict requirements. The paper also points out that the World Bank is in a better position to bridge stakeholders and resolve the paucity of consultation and consensus, which is a major drawback in the Ethiopian higher education reform process.

Keywords: higher education reform; methods of influence; policy transfer; disinvestment; intergovernmental organizations 


\section{The indelible footmarks of the World Bank in the higher education of the developing world: The case of Ethiopia}

\section{Introduction}

Several factors have influenced the global higher education (HE) landscape in the past few decades that resulted in the shift of approaches, paradigms even philosophical foundations on the role of HE in society. The inclination of the West to the emerging knowledge-based economy has become the most influential. Being dominated by such trends in many developed countries, in the past few decades, Intergovernmental Organizations (IGOs) involved in economic development, such as the World Bank (WB), have had to struggle to address the question: where would be the place of the developing nations and the role of their universities (Collins \& Rhoads, 2008).

IGOs like the WB, the OECD, the EU and UNESCO have played a crucial role in the globalization and internationalization of HE. The WB in particular, has been the driver of change in the HE of the developing world for the past four decades or so. Besides giving loans, the Bank which calls itself a 'knowledge Bank' (WB, 2003, p. iv) has used different methods to steer the direction of HE development in the least developed countries. Its mighty financial and institutional capacity gave it the privilege not only to influence governments but also to get other organizations and agencies lined up under its global leadership. Concurrent to its strength and influence, the WB has also been strongly criticized for its approach towards HE, and at times it is viewed as 'anti-HE'. Some even question the legitimacy of its involvement in the education sector like Youssef (2005, p. 4) who asks: 'what place does a bank have in guiding the educational priorities of developing nations?'

In Ethiopia, the WB's activities in the HE sector goes as far back as the 1980s, and its influence has become even more visible since the mid of the 90s. Since the turn of the century Ethiopia has undertaken significant reforms in its HE system assisted by the WB. Ethiopia is also named one of the top recipients of WB loan in HE (Salmi \& Bassett, 2010). But, as much as it gets loans it is also provided with conditions to fulfill, reform advices and policy recommendations that have subsequently taken effect, as it can be substantiated by a simple comparison of the bank's recommendations and the changes that took place (Araia, 2004; Molla, 2012). As an international policy transfer agent, the influence of the Bank needs to be examined and questioned: what type of influence is produced through the reforms? What mechanisms are used to bring them in to effect? Are the reforms based on the realities of the country and do they fit in its overarching development interest of the country? Are they owned by the concerned stakeholders?

The following sections attempt to answer these questions by looking deeper in to the methods used by the Bank and the nature of its influence, followed by some criticisms on its approaches. But first a brief introduction to the role of the WB as a development partner to Ethiopia is presented, followed by a description of the methodology and theoretical framework employed.

\section{Methodology and Theoretical Framework}

The build-up of this paper relies on literature review and document analysis as its source of evidence. Due to the limitation of literature on the Ethiopia-WB relationship, the paper also takes in to consideration similar researches, articles and publications that describe and analyze the relationship between the WB and other developing countries. It also analyzes WB documents such as official reports, publications and project documents, as well as official documents of the government of Ethiopia such as proclamations, regulations, reports, and statistical abstracts.

Within the general concept of policy transfer, the Dolowitz and Marsh (2000) model of 'policy transfer 
The indelible footmarks of the World Bank in the higher education of the developing world

continuum' is employed as a theoretical framework. Policy transfer is conceptualized as an emulation process in which knowledge about policies, administrative arrangements and institutions in one time and/or place is used in the development of policies, administrative arrangements and institutions in another time and/or place (Dolowitz \& Marsh, 1996). It involves a number of actors (internal and external) and covers wide range of issues in the policy making and implementation process - from general ideological orientation to the daily routines of administrative practices (Ahmed, 2009).

Policy transfer may also be voluntary, one in which a rational analysis of what is beneficiary for the receiving system determines what element of policy and how shall be adopted; or it could be coercive, one in which various factors and actors force the receiving system to adopt and materialize certain policy elements. This is best described in the policy transfer continuum model of Dolowitz and Marsh which extends 'from lesson-drawing to the direct imposition of a program, policy or institutional arrangement on one political system by another' (Dolowits \& Marsh, 2000, p. 13). Using this model, and considering the WB as an international policy transfer agent, this paper explains the nature and methods of the Bank's influence on the Ethiopian HE.

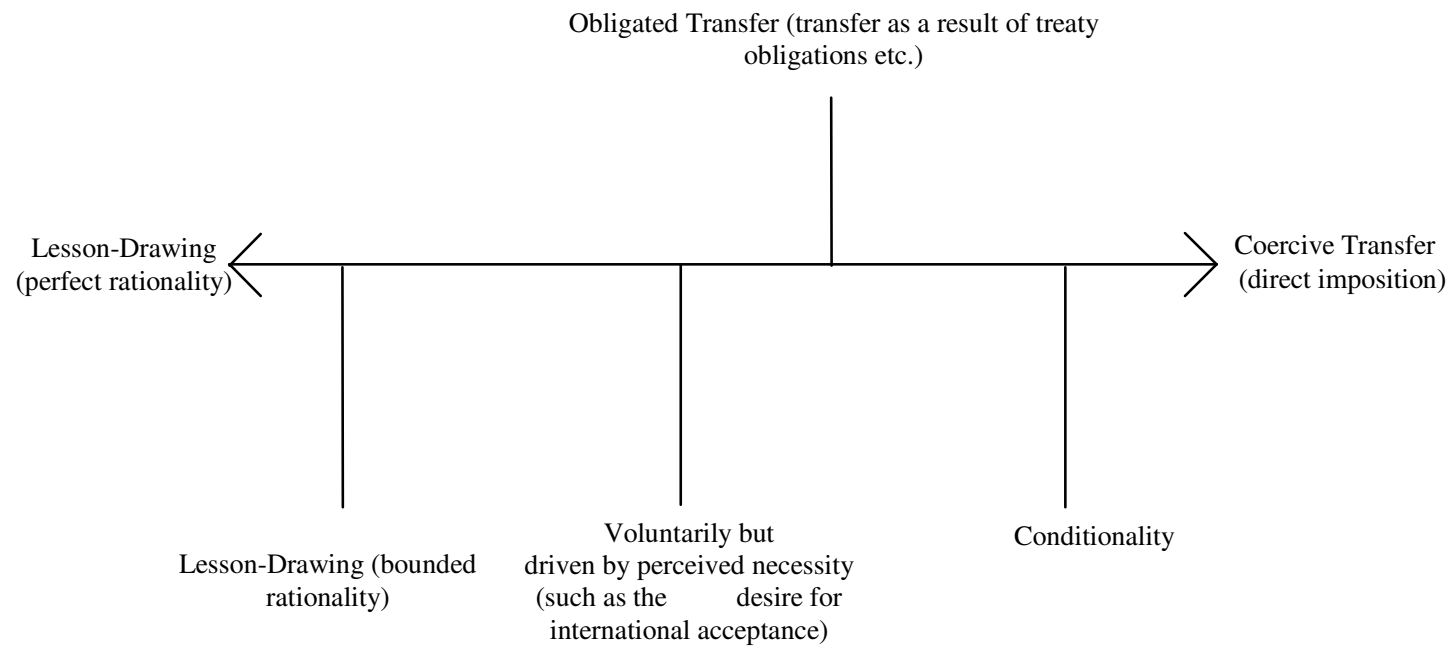

Source: Dolowitz and Marsh, 2000 p. 13

\section{The World Bank as Ethiopia's Development Partner}

The WB has long been Ethiopia's primary development partner. Ethiopia obtained its first loan from the Bank in 1950 for its 'Highway Project (01)' in the amount of 5 Million USD. Over the years, the area of partnership has diversified and Ethiopia has grown as one of the highest recipients of loan, amounting billions of dollars. The first education loan came in 1966 with the amount of 7.2 million USD, focused on improving primary education. Since the end of the 1980s there were nine major projects related with higher education with a total amount of 519.5 million USD in loan (about 134.9 million USD directly committed to HE).

Emerging in the 1950s with the establishment of Addis Ababa University, the Ethiopian higher education system has remained very limited in size until the end of the 1990s. During this time, both the government of Ethiopia as well as the WB focused on lower levels of the education sector. This is also evidenced in the distribution of higher education related loans - only one in 1988 and the remaining five since the end of the 1990s.

Table 1

WB funded/supported projects in the tertiary education sector

Year of

approval
Project title
Amount (Mill. Share of Status USD) 
Woldegiyorgis, A. A.

\begin{tabular}{|c|c|c|c|c|}
\hline 2013 & General Education Quality Improvement Project II & 130 & $12 \%$ & Active \\
\hline 2010 & EFA FTI CF Grant 2 - GEQIP APL & 98 & $12 \%$ & Closed \\
\hline 2008 & $\begin{array}{l}\text { General Education Quality Improvement } \\
\text { Project }-A P L(G E Q I P)\end{array}$ & 50 & $12 \%$ & Closed \\
\hline 2004 & Private Sector Development Capacity Building Project & 24 & $8 \%$ & Closed \\
\hline 2004 & Post Secondary Education Project & 40 & $80 \%$ & Closed \\
\hline 2001 & Distance Learning LIL & 4.9 & $18 \%$ & Closed \\
\hline 2001 & $\begin{array}{l}\text { Conservation and Sustainable Use of Medicinal Plants } \\
\text { Project }\end{array}$ & 2.6 & $67 \%$ & Closed \\
\hline 1998 & Education Sector Development Project & 100 & $16 \%$ & Closed \\
\hline 1988 & Education Project (07) & 70 & $70 \%$ & Closed \\
\hline
\end{tabular}

Source: Compiled by the author from the web site of the World Bank.

Note. a) Data is correct as of February, 2014; b) these are projects that explicitly mention 'tertiary education' as a benefiting sector. Other projects may also have small portions connected with the sector - e.g. education projects 01 to 06 (amounting $154.7 \mathrm{million}$ USD) do not specify whether HE is covered or not.

\section{World Bank's Methods of Influence}

Since its establishment, the WB has used a number of different methods to influence developing countries to make the necessary changes in line with the development goals of the Bank. Some of these methods, in fact, have been strongly criticized for serving specific 'covert' ideological agenda and interests of some western, than that of the developing, countries. Proponents of the Bank explain that the methods are designed and applied in line with the changing circumstances of the world and depending on the existing knowledge and strategy of the Bank. Indeed over the years, the methods used by the Bank have changed in nature and in their target outcomes.

The Bank generally uses similar methods to influence developing countries even though there are certain interpretations and technicalities of application pertinent to the respective countries. Besides it is also important to note that these methods are general in nature while there are some specifics related to the area of lending - e.g. while conditionality is a general method, the conditions put forward may be different for education lending and infrastructure lending. Review of available literature on the work of the Bank and investigation of the Bank's documents reveals that the following are some of its most commonly used methods of influence. Here, these general methods targeting the developing world in general are presented with explanations, whenever possible, how they specifically materialized in the Ethiopian case.

\subsection{Policy Prescription}

Convinced with the viability of certain economic theory, the WB, during the period from 1980 until about 1994, came out with a strong position on the objective of development policy for the world's least developed countries - the achievement of rapid and sustained economic growth. This seemingly 'incontestable' objective was not only shared by the Bank's sister organization the IMF, but was also at the center of the outlook of Washington based policy thinkers and policy makers, described by John Williamson's 'Washington consensus' (Pender, 2001).

This objective was repeatedly articulated and reflected in the publications of the Bank over those years. Development was measured in terms of GDP per capita, and the adoption of the WB and IMF policy framework was seen to be the key to achieving development objectives. It was a time of direct policy subscription by the WB and its partners to the developing world. Loans from the WB, IMF and regional development banks, and aid from bilateral donors became available only when the recipient government agrees to implement a set of economic policy reforms shaped based on the development model of the WB. Ethiopia was not impervious of this approach by the Bank, even though the socialist regime in power until 1991 was typically resistant. Ethiopia's much higher attention on lower level education, compared to the tertiary level, and the privatization of HE in the 1990s can be considered as the manifestations of this influence.

\subsection{Conditionality: from SAP to CDF}


The indelible footmarks of the World Bank in the higher education of the developing world

Conditionality, being a bit moderate than direct policy subscription, is applied in a similar fashion and to a similar end. What is different is that while around the end of 1990s the WB redirected its conception of development objectives and retreated from direct policy subscriptions, conditionalities remain widely applied even to date. First proposed in 1979 by the then WB President Robert McNamara, conditionalities during the time of Structural Adjustment Program (SAP) was 'direct and strict in linking financial assistance to the adoption of a particular set of policies recommended by the WB' (Pender, 2001, p. 399).

After the validity of the WB's approach to development being questioned for about a decade, and after much controversy and loss of trust towards the Bank, by the end of the 1990s the Bank moved to what is called Comprehensive Development Framework (CDF). CDF has been widely recognized for its broader perspective on development, going beyond economic growth. It was acclaimed to have focused on the context and realities of the developing countries; and to embrace partnership, than vertical hierarchical relation, as a way forward (Collier, 2000).

This move from SAP to CDF has been explained in favor of the WB, implying that the previous approach of the Bank has enabled more developing countries to move to what the Bank regards as 'good policy environments', and therefore a change of approach was necessary. Nonetheless, it is necessary to ask: has there been a real change in how things work? Pender (2001) argues that conditionality has only been renegotiated in line with the changing emphasis of the WB's definition of development. It is evident that conditionality has remained being one of the powerful means of the WB to influence developing countries. The 2006 report of Eurodad, for instance, indicated that there were on average 67 conditions attached to each WB loan. The same report showed that Ethiopia also had 67 conditions attached to the then active loans from the WB and the IMF (Eurodad, 2006).

In education, the predominant conditions often presented by the WB were:

(1) shifting public expenditures away from vocational and higher education toward academic and basic education; (2) increasing the private cost for attending universities; and (3) installing loan schemes to set off the financial burden on individuals who must then face high tuition increases for higher education' (Heyneman, 2003, p. 325).

In its 2002 publication the WB has also set out its principles of operation for intervention in client countries, which can be interpreted as the implication of the conditionalities in play:

'strategic planning at national and institutional level, promoting autonomy and accountability in the sector, focus on capacity enhancement and attachment with overall development plan of the respective country' (WB, 2002, pp. 119-120).

\subsection{Technical Assistance}

The provision of technical assistance is another method through which the ideologies, philosophies and goals of the WB penetrate the loan receiving developing countries. The Bank has been giving technical assistance to different countries for decades as one form of supporting the development endeavor of the recipients. This has been practiced in wide spectrum of development including higher education. The Bank has identified technical assistance and Technical Assistance Loan (TAL) as optional methods of support where governments show interest and initiation for change in their tertiary education, but challenged by political and technical situations. In such a case the use of those alternatives 'would be preferable for assisting governments in moving the reform agenda forward' (WB, 2002, p. 121). In Ethiopia, overall civil service capacity building program of the Federal government, introduced in 1996, constituted a series of measures laying the base for what was later developed in to Capacity Building Strategy and Program (CBSP), which also includes the higher education sector. The WB, since 1998/1999, substantially increased its support for CBSP and later, beginning in 2001, it took charge of coordinating activities of bilateral and multilateral agencies in the implementation 
process (Oulai, Lugaz, Minas, \& Teklehaimanot, 2011). In the HE sector, the Bank provided support extending from hiring foreign professors for newly established universities and in subjects of short supply of skilled Ethiopians, to the assignment of experts assisting in federal ministry of education and other institutions.

Technical assistance, as can be observed, has provided the Bank not only with access to the implementation aspect of policy through its personnel and affiliate experts, but also the power to steer and influence the whole process through coordinating all the bilateral and multilateral agencies concerned with capacity building.

\subsection{Through Other Organizations}

Credited to its multi-dimensional and multi-level engagement in developing countries, the WB has become an ineludible actor in the international development interplay. Countries desperately try to get the WB on their side as if a development initiative that is not supported, or at least endorsed, by the Bank is doomed to fail. This happens because of the Bank's reputation and influence on donors and development agencies all over the world. Besides having strong relationship with its sister organizations which are collectively known as 'the Britton Woods organizations', the Bank, thanks to its financial strength, has built a huge influence over other organizations and mostly takes the lead in programs that are hosted by the joint effort of many bilateral and multilateral agencies. The other organizations with a very strong influence on the global development of education, OECD, the UN agencies UNDP and UNESCO are close allies of the WB.

Noting this potent influence of the Bank in the global arena of the education development, Youssef points out that, the WB has achieved much clout with other donors and international organizations. He furthers that because the WB takes a leading role in different international working groups on education policy, it has forwarded analyses and recommendations that invariably affect the agendas of other lending agencies (Youssef, 2005). Similarly, Salmi and Bassett (2010) note that the WB, in its effort of addressing global public good issues pertinent to education, is working in strong partnership with other multilateral agencies and different university associations and networks in the African continent. As mentioned elsewhere in this paper, in Ethiopia the WB had the role of coordinating the donor community (Martin, Oksanen, \& Takala, 2000) in the development and implementation of the education sector development program giving it all the power to leverage on behalf of all donors.

\subsection{Agenda Setting Through Publications}

The WB has produced a considerable amount of publications on various issues pertinent to HE. While it is difficult to measure the direct impact of these global publications, one can see how important they are in setting the agenda for discussion and policy dialogue. By citing examples from Yemen and Pakistan, Salmi and Bassett (2010) claim that such publications as 'Constructing Knowledge Societies: New Challenges for Tertiary Education' and 'Higher Education in Developing Countries: Peril and Promise' have sparked a huge discussion among the academia, the practitioners as well as the media. In effect, a number of countries have initiated policy reforms and developed new strategies following the recommendations of these publications. The Bank's major publications that, over the years, have depicted the direction and approach of the Bank towards HE, include: Higher Education: Lessons of experience (1994); Knowledge for development: World Development Report 1998/99 (1999); Higher Education in Developing Countries: Peril and Promise (2000); Constructing Knowledge Societies: New Challenges for Tertiary Education (2002); Education Sector Strategy update (2005);and Accelerating catch-up: Tertiary education for growth in Sub-Saharan Africa (2009). The Bank has also published documents on specific issues in HE such as financing and quality assurance. In addition to these, the comprehensive document exclusively on Ethiopian HE: Higher education for Ethiopia: Pursuing the vision (2003) has provided all-rounded recommendations of the Bank which had strong bearing on the reforms of the following years. 
4.6 Negotiation

Experts of the Bank Salmi and Bassett emphasize the importance of negotiation and consensus building in the experience of the WB saying that

'the Bank recognizes that, in higher education, more than in any other area of education development, reform programs and innovative approaches have little chance of success unless careful attention is paid to the political economy of change; stakeholder consultation and consensus building are as important as a technically sound design' (2010, p. 595).

They further assert that the experience of the WB in several countries underscores the need for continuous policy dialogue and vision sharing with all stakeholders to ensure the sustainability of reforms.

These claims attribute the Bank the practice of negotiating with not only the governments, but also other stakeholders of the higher education sector in the loan receiving country. This is also reinforced in Collins and Rhoads (2008) who, referring to the experiences of Uganda and Thailand, noted that national governments have the opportunity to negotiate what they are willing to accept in the terms and conditions of the loan agreements. But they also observed that there is a noticeable variation in how much projects and the associated conditions are aligned with national initiatives.

The very important question that has to be asked here is what does the negotiation process look like? Are the negotiating parties on equal grounds? Do the governments of the loan seeking countries have the options of not accepting conditions and the luxury of saying 'no'? Considering the fact about the bargaining power of the countries and the strength of the Bank not only in its own but also in its influence on other donors, it is not difficult to realize how the negotiation is imbalanced in favor of the Bank.

\subsection{Consultancy}

It often happens that countries seek the consultancy of the WB. The Bank has also conducted and documented a number of sector studies for different countries where it makes analysis of their situation, identifies problems and recommends solutions and directions for policies and reforms. A case in point is the 2003 sectoral study of the Bank on the Ethiopian HE (Higher Education for Ethiopia: Pursuing the vision) after which the Ethiopian government shaped several major reforms. It is not surprising that countries seek the service of the Bank in this regard, considering its rich experience and the possible impact of reforming upon its recommendation in terms of acceptance and securing finance. But now days even countries that no longer need or want to borrow from the Bank such as china, Kazakistan and Malysia actively seek policy advice from the Bank on issues of education reforms (Salmi \& Bassett, 2010). This evidently demonstrates the Bank's opportunity to influence the higher education reforms even in countries it is not lending to.

In general, these major methods of influence represent how strong the WB is in gearing the global agenda of development in general and of Ethiopian higher education in particular. The globalization of higher education and most reforms of the developing countries that took place in the past more than two decades are invariably influenced by the WB. In Ethiopia, higher education reforms in the past fifteen years have everything to do with the influence of the WB which came in one or another form of these methods of influence.

Put on the policy transfer continuum, publication and consultancy service represent the most voluntary (the softest) methods of transfer. In these cases the Bank does not directly interfere in the policy process of the Ethiopian HE - publication is put out triggering discussions and inviting the government to consider points of importance, while consultancy materializes only upon the invitation of the government. On the contrary direct policy prescription and strict conditionality incline to the coercive end. Negotiation, technical assistance and influence through other organizations lie somewhere in between. These methods seem to constitute both voluntary and coercive elements. While the methods are designed to be voluntary in nature, their practical application is 
Woldegiyorgis, A. A.

affected by numerous factors that disfavor the government.

\section{Nature and Extent of the Influence}

In general the influence of the WB on the higher education of developing countries (including Ethiopia) in the past can be classified in to two phases, before and after mid 1990s - the phase of discouraging and the phase of encouraging respectively. The 1980 World Development Report marks the beginning of the first phase where the Bank advocated more investment on basic education at the expense of higher level. This was mainly driven by the Rate of Return (ROR) analyses which suggested that for low income countries the yield obtained from investment in basic education is much higher than that spent in higher education (Collins \& Rhoads, 2008). The second phase, which commences in the end of the 90s, showed the Bank's change of heart on HE in developing countries. This dramatic shift, from discouraging to advocating investment in higher education, is best demonstrated in the publication of the Bank which claims that if developing countries do not effectively improve their HE systems, they 'will find it increasingly difficult to benefit from the global knowledge-based economy' (WB \& UNESCO, 2000, p. 9).

In line with this shift of policy, the Bank in the past fifteen years or so has initiated and supported higher education reforms in developing countries. Salmi and Bassett have identified that:

'the main types of the activities supported by the Bank projects, which are tailored to the needs of the country and the specific requests of the national authorities and the higher education community, may come under one or more of the following headings: Financial reforms, governance and management reforms, quality improvement, institutional diversification, science and technology development, and vision development, strategic planning, and consensus building at both the national and institutional levels' (2010, p. 592).

In Ethiopian HE every major reform that has taken place in the last fifteen years is influenced, shaped or even crafted by the WB. Taking a look at the major reforms in relation with the policy recommendations of the Bank to Ethiopia and consideration of the number of projects financed by the Bank which have to do with reforms in the higher education sector (along with the instruments of influence the Bank leverages) would demonstrate the point. The major areas of influence and the resultant changes are broadly related to the introduction of market forces, the assurance of quality and reforming governance.

Privatization, one of the market mechanisms in HE, is at the center of what the WB $(1994,1999,2002)$ calls 'sound economic policy'. The private sector is praised to be much better than the public in achieving the most desired public policy goal of efficiency. In line with the Bank's policy recommendation, Ethiopia opened up the HE sector for private investment in mid 1990s. Within fifteen years, the number of accredited private HEIs, with undergraduate and postgraduate programs, grew from zero to 44 in 2009/2010 academic year, enrolling about 18\% of the total student body (MOE, 2011). The Bank is still pushing with more privatization. In its 2009 policy report on the Sub Saharan Africa (SSA), it called for more emphasis by governments fields of strategic priority such as science and technology (WB, 2009), leaving the social sciences and the humanities for private investment.

Another dimension of the market forces in higher education, advocated by the WB, is Cost-sharing. Drawing on the thesis that reduction of public spending in HE, by letting individual students pay directly for a service they receive, would maximize efficiency in resource utilization, the WB had consistently urged Ethiopia, throughout the 1990s, to introduce a cost sharing scheme. Finally the 2003 'Higher Education Proclamation' (later revised in 2009) provided that any Ethiopian student studying in a public institution and who is not required to pay an in-advance tuition fee shall contribute, in cash or in service, to cover the cost of his/her education. This was also supplemented by the subsequent regulation (No. 91/2003) of the Council of Ministers addressing the implementation aspect.

Likewise, income generation by public HEIs is another recommendation by the WB $(2002,2003,2009)$ so as 
to reduce their dependence on government funding. While public universities are still massively dependant on public funding, the major change in policy came after the recommendation of the WB (2003) citing the good examples of Addis Ababa College of Commerce and the agricultural colleges at Hawassa and Jimma Universities. Accordingly, the government, through its HE proclamation, demanded public universities to gradually move away from public funding through mobilizing resources for themselves in different ways, for example, marketising their research and advisory services and establishing for-profit enterprises. Similarly income generation has been emphasized as an area that requires further improvement both in the 3rd and 4th Education Sector Development Plans (ESDP) (MOE, 2005, 2010).

Following the shift in the WB's position on the role of higher education in development of poor countries, its publications (WB, 1999, 2002, 2003, 2009; WB \& UNESCO, 2000) ardently encouraged governments to make more investment in higher education, resulting in massification of the sector in many countries such as Ethiopia. In 2000 access to HE in Ethiopia was among the least in SSA, expressed by $0.8 \%$ GER (WB, 2003). In 2008/09 GER has reached 5.3\% and is targeted to reach $9.3 \%$ in 2014/15. Expressed differently, total enrollment has increased from 42,132 in 1996/97 to 319,217 in 2010/11 and it is planned to reach 467,445 by 2014/15 (MOE, 2000, 2005, 2010). The number of public universities has also risen from two in 1998 to 22 in 2010, and ten more under establishment.

Quality assurance is another area where the footmarks of the WB are strongly visible in the Ethiopian HE. The Bank suggested that lack of relevance and poor quality of HE in SSA in general (WB, 2009) and in Ethiopia in particular (WB, 2003) emanate from lack of qualified staff, outdated curriculum, and declining spending on physical facilities. Molla (2012) notes that, in line with the Bank's recommendations, the government of Ethiopia has reviewed and updated university curricula; introduced new programs in areas of computer science, agriculture, engineering and other science fields; expanded graduate level programs; improved pedagogical competence of university teachers through professional development programs; and institutionalized the Higher Education Relevance and Quality Agency (HERQA) and the National Pedagogical Resource Centre (NPRC).

The concept of decentralized power and autonomy of institutions at the expense of limited state intervention is an inherent feature of the neoliberal ideology (Molla, 2012). Hence, the 2003 recommendations of the WB for Ethiopian HE called for decentralization and autonomy of HEIs by devolving the state power. The Bank also stressed the need for effectively coupling the autonomy of HEIs with an appropriate set of accountability mechanisms. Accordingly the government, instead of direct intervention, favored autonomous institutions (FDRE, 2003 , 2009) limiting itself, in principle, to steering using regulatory frameworks and supervisory institutions. The introduction of strategic plan agreement and block grant budgeting system, and the establishment of internal and external quality control mechanism along with the Higher Education Strategy Center (HESC) fall under such reforms. Nonetheless, it should be noted that while the government steering is limited by the organizational capacity of the oversight agencies, institutional autonomy in Ethiopia is only partial. Public universities, for instance, have little or no control on student admission at undergraduate level; and top members of the university governance body are appointed by the government.

In summary, it can be noted that while the above mentioned are only the major areas of reforms that are influenced by the WB, each one incorporates a wide range of programs, projects and activities. A detailed consideration of each would reveal that the role of Bank in the policy transfer process is extended from the system level politico-economic philosophical orientation, as in privatization of $\mathrm{HE}$, all the way to strengthening specific institutions in their implementation capacity, as in employing WB experts in the ministry and particular universities.

\section{Criticisms of the Bank}

As much as its reputation as a development partner to the entire developing world, and the significance of its contribution for the same, the WB has also been severely criticized at many levels for how it interprets and 
approaches development issues and how it attempts to get its development goals achieved by taking roots in the developing countries. The criticisms, for the purpose of convenience, are presented here in a mix of those general to the whole of SSA and particular to Ethiopia; and general to the whole of the Bank's development activities and particular to that of higher education.

The overarching criticism against the WB over the years, particularly on its activities in the developing world, is its advocacy of the politico-economic ideology of neo-liberalism and its insistent push for its acceptance in the developing countries through policy subscription (Molla, 2012; Bollag, 2004; Collins \& Rhoads, 2008; Pender, 2001). Given the fact that the world was dominated by the cold war since the establishment of the Bank to the 1990s, and that the dominant contributing countries to the Bank advocated the neo liberal ideology, the Bank was in no position to be independent of the pressure. But some are still skeptical about the 'real purpose' of the Bank in its involvement in developing countries (c.f. Collins \& Rhoads, 2008). This ideaological orientation had impact on the overall direction of the Bank towards development, and by implication to that of higher education. The then socialist regime in Ethiopia was typically resistant to these 'western value ladden' policy subscriptions of the WB, partially explaining the limited involvement of the Bank in Ethiopia up until the beginning of the 1990s (From 1974 to 1991 Ethiopia was ruled by a socialist military government).

The WB development discourse and conditionalities are said to have been informed basically by two weak policy assumptions. First, the conditions that resulted from ROR analyses demonstrating that investment in higher education was less productive than investing in primary and secondary education. Publications of the Bank from mid 80s to mid-90s called for cut back of investment in higher education in the name of more efficiency and more egalitarian distribution of resources at the primary and secondary levels. This tendency affected the ability of the developing countries to support adequate development of their higher education systems (Collins \& Rhoads, 2008). Yizengaw (2005) on his part notes that many of Ethiopia's partners and donors [including the WB] argued, until recent years, that Ethiopia should not expand its higher education sector, but focus only on universalizing access to primary education. As a result, in Ethiopia, as in the rest of SSA, higher education remained for a long time underemphasized and underdeveloped.

On the contrary, while he recognizes that in Africa the WB is perceived to be 'anti higher education', Fredrikson (in Bollag, 2004, p.ii), argues that the Bank's approach to higher education has been 'pragmatic and quite supportive in cases where the conditions were conducive to promote indispensable reforms'. This argument is further substantiated by showing the higher rate of education lending for HE, in SSA, during the time the Bank is said to have abandoned HE.

The second area the WB is said to have had inadequacy in its policy assumptions is its advocacy of privatization and market rule for HE in SSA. On one hand, it is the neoliberal agenda that encourages limited government intervention in public services, on the other hand the misunderstanding of (or lack of concern for) the realities in SSA, that led the Bank to push for privatization. Referring to the case of Uganda as an example, Collins and Rhoads (2008) argue that in developing countries, where there is weak private sector, implementing decentralization and privatization is difficult. They also note the importance of the private sector as a supplementary force, and underline the risk involved with attempting to replace or undermine the public sector by a private one. Molla (2012) on his part stresses that when HE is left for the market forces alone, the benefits will be unequally distributed leaving out disadvantaged groups who have little to afford the cost of their education at market price.

The reporting requirements which are hardly consistent with national systems, the commitment of most of the support for technical assistance, and lack of understanding and willingness to support sustainable and long term capacity building efforts, are also in the list of the complaints of the Ethiopian government in its relation with HE development partners in general, and the WB in particular. Yigengaw (2005) (who then was a vice minister of education) elaborates that the specific requirements for reporting which are different from the national system create poor performance in disbursement and utilization of funds for the intended use in due time; and hiring 
The indelible footmarks of the World Bank in the higher education of the developing world

expats reduces the chance for local capacity development. He singles out the WB for putting prerequisites as conditions for loan agreements. On a more operational level, the introduction of cost recovery schemes as part of the cost sharing policy, the requirement of labor demand studies before expansion, and the emphasis on fiscal and budgetary matters than on capacity development are some of the examples he identified as bottlenecks posed by partners in the policy development process of the Ethiopian HE. What adds to this is the lack of consultation in the process of developing HE programs. A greater degree of consultation could increase the possibility to find a common way of doing things between the national system and the Bank's requirements.

Nonetheless, against all the criticisms that the WB prescribes policies and provides too many and too strong conditions, Bollag (2004) claims that if institutions and national systems find their problems and develop their solutions, the Bank is flexible enough to provide additional funding to support specific elements of these strategic plans.

\section{Summary, Analysis and Conclusion}

The WB, over the past several decades has played a pivotal role in the development of HE in the developing world in general, and in Ethiopia in particular. It uses different mechanisms and tools to influence the direction of developing countries with regard to the role of HE in development - from policy prescriptions and coercive conditions to negotiations, publications and consultancy services. It has steered the global HE agenda in a remarkable magnitude. Not only does it work with other bilateral and multilateral organizations, but it also strongly influences their directions. On the other hand, over the years, the WB has been severely criticized. Its biased ideological orientation to the neoliberal camp, its alleged tendency to serve the interest of the superpowers of the world (particularly of the US) than that of the developing countries, its misconception of the realities in the developing world and decisions informed by wrong policy assumptions are some of the points of criticism.

All in all, the Bank has strongly influenced the Ethiopian HE. As a policy transfer agent, it has touched a wide area of policy formation and implementation extending from the ideological direction of market provision of $\mathrm{HE}$ to the reformation of administrative practices and improving implementation efficiency. In so doing, it has used various methods of influence that range from as voluntarily as the Ethiopian government seeking help from the Bank, to as coercive as direct policy prescription and strict conditionalities.

Since the beginning of the 1990s, the Bank has supported a number of projects and it is arguably the most influential of Ethiopia's partners in the development of education, and HE in particular. While there is a tension among the international donor community for taking a lead in influencing the education development path in Ethiopia, the WB mostly took the leading role by coordinating development aid on behalf of all donors and partners (Martin, Oksanen, \& Takala, 2000). It has informed, advised and supported the development and implementation of the overarching education development plan of the Ethiopian government - ESDP. The Bank has published a number of documents, both general and specific to Ethiopia, in which it addressed issues in $\mathrm{HE}$ and provided policy recommendations. The 2003 publication of the Bank - Higher Education for Ethiopia: Pursuing the vision - is typically the most influential that paved the way for the major reforms that took place in consequent years.

Based on the recommendations of this document and others $(2005,2009)$ and with the technical assistance of the Bank, Ethiopia has undertaken major reforms in the past decade besides pushing forward with the expansion of the sector. It promulgated its first ever higher education proclamation in 2003 and later revised in 2009; established supporting and oversight agencies and centers (HERQA, HESC, NPRC); introduced the cost sharing program; created encouraging incentives for private HEIs; strengthened its production of academic personnel by promoting Addis Ababa University in to a graduate university and opening graduate programs in other universities; opened up a national scholarship program for women to increase the number of female academic staff; provided for greater autonomy of institutions through block grant budgeting and decentralization of power (though the practical application is far from success); introduced the 70:30 student intake ratio for science and technology to social 
science and humanities and opened new institutions of science and technology; commenced capacity development programs for management of universities; and launched ICT programs in all universities.

Nonetheless, this tremendous influence of the WB does not go without criticisms and complaints. Mainly, as in the case of other SSA countries, Ethiopia has suffered from the wrong directions of the Bank in disinvestment and too much orientation to private HE provision. Moreover, as Yigengaw (2005) noted the Bank: puts conditions that do not consider the realities, and are not related to the overall development strategy, of the country; focuses too much on budgetary and financial matters; requires for specific reporting mechanisms to take effect; provides direct technical assistance at the expense of capacity building, even pushes for the employment of [foreign] experts in the ministry and other institutions. In his remark, he calls for any development support to be harmonized and linked to the decision making and budget process of the country.

While it is a plausible comment that the WB should consider the realities on the ground and focus on enhancing local capacity, it can be argued that the 'negative' influences of the Bank, in this aspect, are not entirely negative. Considering that Ethiopia has poor record on transparency and corruption indexes, and that its institutions are weak, characterized by lack of transparent and participatory decision making processes, the Bank is justified to put specific requirements regarding reporting mechanisms and financial administration. Ethiopia's institutional experience compared to that of WB's, and the very low engagement of the academia in the HE development process, could be seen as a viable reason for the WB to encourage more of direct technical assistance and employment of experts that can help effectively push the reforms forward. But it has to be underlined that it shall not be, in any way, used as an excuse for the Bank to shy away from engaging in local capacity development.

In the interest of making the most out of the Bank's assistance for the Ethiopian HE, two points should be emphasized. First, WB's influence in Ethiopia has, so far, paid little attention to research and university-industry relationship, besides recommending Addis Ababa University to become a graduate and research institute. For HE to effectively contribute in the development of the country, research has to be given sufficient attention in a way it will lead to the development of an inclusive innovation system. Research centers should be established, research budget of universities has to be substantially increased, individuals and institutions with better research performance should be rewarded, and university-industry relations should be strengthened.

Second, there is a paucity of dialogue and engagement in the sector. The HE development is driven by the government and donors, and suffers from a serious lack of ownership by the important stakeholders, particularly the academia. There are three competing explanations about the lack of engagement by the academia. First, Bollag suggests that the government lacks the will and experience (capacity) of engaging others, which has left the Bank with no option but dictating the process. He quotes an unnamed western education specialist who has closely followed developments in Ethiopia, who says:

'The Ministry's vision is a good one, but they don't have adequate capacity to manage the reforms, so the tendency is to try to dictate. What they mean by consultations is: you call in the stakeholders, tell them your idea, ask if they have any questions, and then tell them to follow it' (Bollag, 2004 p. 18).

The government provides a different justification by throwing the blame to the academia. Yigengaw (2005, p. 6) claims that, 'overwhelmed by political partisanship, the academia, and the HE community in general, is indifferent about the reform agenda of the government'. The third explanation blames the WB for not taking the initiative to consultation and consensus building particularly by engaging high profile Ethiopian experts in the field. Teferra (2004), in his commentary on the 2003 publication of the WB, criticizes the Bank for involving few incompetent individuals as the 'Ethiopian delegate' who can hardly produce expertise based argument to challenge the Bank.

In all the three explanations the bottom line remains that the development of HE programs and reforms in Ethiopia lack the engagement of major stakeholders. In this regard, it appears that the Bank is in a better position to 
The indelible footmarks of the World Bank in the higher education of the developing world

bridge the gaps by involving experts, engaging all stakeholders in dialogue to build a consensus around the direction and approach that the country has to take in its HE development.

\section{Reference}

Ahmed, H. S. (2009). An analytical understanding of how external sources inform and impact upon Somaliland's national education and teacher education policy making processes. Unpublished doctoral thesis, Brunel University, London, England.

Araia, G. (2004). Reflections on the development of higher education in Ethiopia. Retrieved June 21, 2011, from http://www.africanidea.org/reflections.html

Bollag, B. (2004). Improving tertiary education in Sub-Saharan Africa: Things that work. Report of the Regional Training Conference, held September 23-25, 2003, Accra, Ghana.

Collier, P. (2000). Conditionality, dependence and coordination: Three current debates in aid policy. In Gilbert, C. L., \& Vines, D. (Eds.), The World Bank: Structure and policies (pp. 299 - 324). Cambridge: Cambridge University Press. http://dx.doi.org/10.1017/CBO9780511560002.013

Collins, C., \& Rhoads, R. (2008). The World Bank and higher education in the developing world: the cases of Uganda and Thailand. International Perspectives on Education and Society, 9(8), 177-221. http://dx.doi.org/10.1016/S1479-3679(08)00007-8

Dolowitz, D., \& Marsh, D. (1996). Who learns what from whom: A review of the policy transfer literature. Political Studies, 44(2), 343-357. http://dx.doi.org/10.1111/j.1467-9248.1996.tb00334.x

Dolowitz, D., \& Marsh, D. (2000). Learning from abroad: The role of policy transfer in contemporary policy making. Governance, 13(1), 5-23. http://dx.doi.org/10.1111/0952-1895.00121

Eurodad. (2006). World Bank and IMF conditionality: A development injustice. Retrieved February 03, 2013, from http://www.eurodad.org/uploadedfiles/whats_new/reports/eurodad_world_bank_and_imf_conditionality report.pdf

Federal Democratic Republic of Ethiopia [FDRE]. (2003). Higher education cost-sharing council of ministers regulation no.91/2003. Federal Negarit Gazette, 9(85). Addis Ababa: Berhanena Selam Printing Enterprise.

Federal Democratic Republic of Ethiopia [FDRE]. (2003). Higher education proclamation no.351/2003. Federal Negarit Gazette, 9(72). Addis Ababa: Berhanena Selam Printing Enterprise.

Federal Democratic Republic of Ethiopia [FDRE]. (2009). Higher education proclamation no.650/2009. Federal Negarit Gazette, 15(64). Addis Ababa: Berhanena Selam Printing Enterprise.

Heyneman, S. P. (2003). The history and problems in the making of education policy at the World Bank 1960-2000. International Journal of Educational Development, 23(3), 315-337. http://dx.doi.org/10.1016/S0738-0593(02)00053-6

Martin, J., Oksanen, R., \& Takala, T. (2000). Preparation of the education sector development program in Ethiopia. Paris: Association for the Development of Education in Africa (ADEA).

Ministry of Education [MOE]. (2000). Education statistics annual abstract 1998/99. Addis Ababa: Author.

Ministry of Education [MOE]. (2005). Education sector development program (action plan) III (ESDP III). Addis Ababa: Author.

Ministry of Education [MOE]. (2010). Education sector development program (action plan) IV (ESDP IV). Addis Ababa: Author.

Ministry of Education [MOE]. (2011). Education statistics annual abstract 2009/2010. Addis Ababa: Author. Molla, T. (2012, October 12-13). Neoliberal policy agenda and the problem of inequality in higher education: The Ethiopian case. Paper presented at Globalization, Regionalization and Privatization in and of Education in Africa, Johannesburg, South Africa.

Oulai, D., Lugaz, C., Minas, A., \& Teklehaimanot, H. (2011). Analysis of capacity development in educational planning and management in Ethiopia. Paris: International Institute for Educational Planning.

Pender, J. (2001). From 'structural adjustment' to 'comprehensive development framework': Conditionality transformed? Third World Quarterly, 22(3), 397-411. http://dx.doi.org/10.1080/01436590120061679 
Woldegiyorgis, A. A.

Salmi, J., \& Bassett, R. M. (2010). Transforming higher education in developing countries: The role of the World Bank. In Peterson, P., Baker, E., \& McGaw, B. (Eds), International encyclopedia of education (Vol. 4, pp. 590-596). Oxford: Elsevier. http://dx.doi.org/10.1016/B978-0-08-044894-7.00846-0

Teferra, D. (2004). The World Bank prescription for Ethiopian higher education: The missing antidote in 'pursuing the vision'. Retrieved on February 03, 2013, from https://www2.bc.edu/ teferra/World_Bank_Study_Eth_High_Edu.html

World Bank \& UNESCO. (2000). Higher education in developing countries: Peril and promise. Report by the task force on higher education and society. Washington DC: Authors.

World Bank. (1994). Higher education: Lessons of experience. Washington DC: Author. http://dx.doi.org/10.1596/0-8213-2745-3

World Bank. (1999). Knowledge for development: World development report 1998/99. Oxford: Oxford University Press.

World Bank. (2002). Constructing knowledge societies: New challenges for tertiary education. Washington DC: Author.

World Bank. (2003). Higher education for Ethiopia: Pursuing the vision. Washington DC: Author.

World Bank. (2005). Education sector strategy update. Washington DC: Author.

World Bank. (2009). Accelerating catch-up: Tertiary education for growth in Sub-Saharan Africa. Washington DC: Author.

Yizengaw, T. (2005, May 23-24). Policy development in higher education in Ethiopia and the role of donors and development partners. Paper presented at the International Expert Meeting-Formulas that work: Making Higher education Support more effective, Hague, Netherlands.

Youssef, C. (2005). World Bank priorities in education lending: An ever-changing endeavor. Paterson Review, 6, $1-29$. 